\title{
Crystal Structure of 2,6-Dioxa-14,18-diazatricyclo-[18.4.0.0 $\left.{ }^{7,12}\right]$-tetracosa- 7,9,11,20,22,24(1)-hexsaene-diacetatopalladium(II)
}

\author{
Tuncer HöKELEK, ${ }^{* \dagger}$ Orhan BÜYÜKGÜNGÖR,** Elif Ece İLTER, *** and Zeynel KILIÇ**** \\ *Hacettepe University, Department of Physics, 06800 Beytepe-Ankara, Turkey \\ **Ondokuz Mayls University, Department of Physics, 55139 Kurupelit-Samsun, Turkey \\ ***Ankara University, Department of Chemistry, 06100 Tandoğan-Ankara, Turkey
}

\begin{abstract}
In the title complex, $\mathrm{C}_{24} \mathrm{H}_{32} \mathrm{~N}_{2} \mathrm{O}_{6} \mathrm{Pd}, \mathrm{Pd}$ (II) ion, is coordinated bidentately to $\mathrm{N}$ atoms of the macroring and monodentately to $\mathrm{O}$ atoms of the acetate ligands, in a square-planar geometry. The etheric oxygens of the macroring are not bonded to the metal ion, but are interestingly bonded to each hydrogen of the benzylic $\mathrm{CH}_{2}$ groups. On the other hand, beside of the intramolecular $\mathrm{C}-\mathrm{H} \ldots \mathrm{O}$ bonds, the strong intramolecular $\mathrm{N}-\mathrm{H} \cdots \mathrm{O}$ hydrogen bonds, between the two acetate oxygens and $\mathrm{N}$ atoms of the macroring, also contribute to stabilization of the molecular structure. It belongs to the space group $\mathrm{Pbca}$ with cell parameters $a=14.1507(6), b=16.9866(7), c=20.4128(11) \AA$.
\end{abstract}

\section{(Received December 2, 2005; Accepted February 7, 2006; Published on web March 27, 2006)}

In contrast to the metal-ion chemistry of macrocyclic multidentate ligands, incorporating all of the ether-oxygens (crown ethers) or all nitrogen donor atoms (macrocyclic polyamines), the chemistry of mixed oxygen-nitrogen, $\mathrm{O}_{\mathrm{x}} \mathrm{N}_{\mathrm{y}}(x, y$ $=2,3,4, \ldots)$, donor type macrocycles has received less attention. On the other hand, the incorporation of nitrogen-oxygen donor

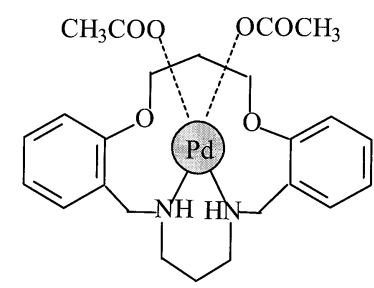

Fig. 1 Chemical diagram.

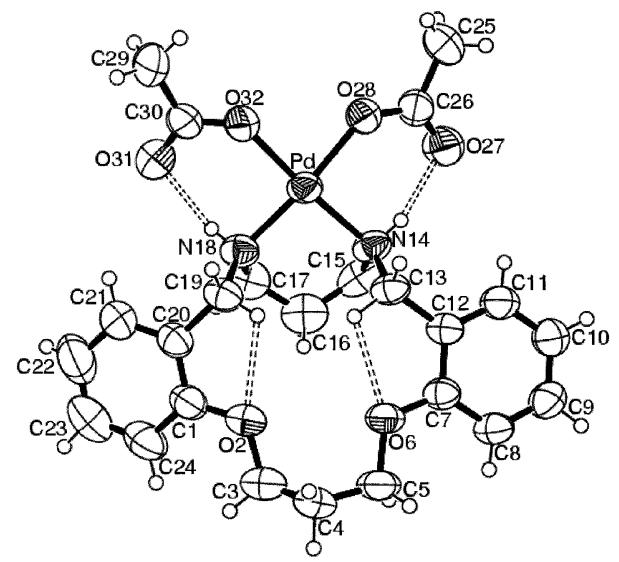

Fig. 2 Molecular structure of the title compound with the atomnumbering scheme. The thermal ellipsoids are drawn at the 50\% probability level.

$\doteqdot$ To whom correspondence should be addressed.

E-mail: merzifon@hacettepe.edu.tr atoms in the macrocyclic rings has increased the affinity for transition metal cations. These kinds of applications are of fundamental importance for broad areas of coordination and bio-chemistry. ${ }^{2}$

Hence, a number of mixed macrocyclic multidentate ligand complexes have been extensively investigated in order to

Table 1 Crystal and experimental data

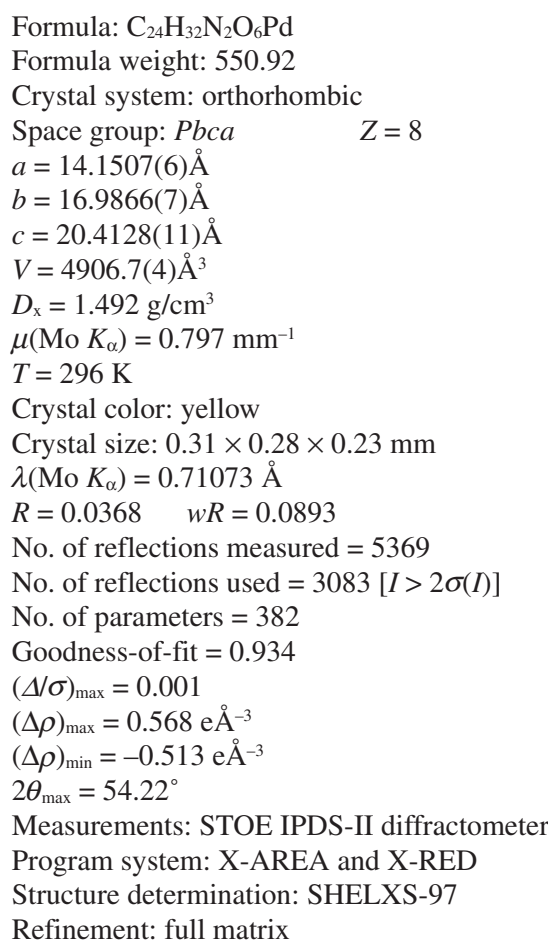

CCDC 274486 contains the supplementary crystallographic data for this paper. These data can be obtained free of charge from The Cambridge Crystallographic Data Centre via www.ccdc.cam.ac.uk/data_request/cif. 
Table 2 Final atomic coordinates and equivalent isotropic thermal parameters

\begin{tabular}{|c|c|c|c|c|}
\hline Atom & $x$ & $y$ & $z$ & $U_{\text {eq }}$ \\
\hline $\mathrm{Pd}$ & $0.451671(17)$ & $0.187884(14)$ & $0.397043(15)$ & $0.05917(10)$ \\
\hline $\mathrm{C} 1$ & $0.4912(3)$ & $-0.0823(2)$ & $0.2698(2)$ & $0.0700(10)$ \\
\hline $\mathrm{O} 2$ & $0.5375(2)$ & $-0.09780(16)$ & $0.32654(17)$ & $0.1010(10)$ \\
\hline $\mathrm{C} 3$ & $0.6047(5)$ & $-0.1616(3)$ & $0.3280(3)$ & $0.144(3)$ \\
\hline $\mathrm{C} 4$ & $0.6283(4)$ & $-0.1857(3)$ & $0.3880(3)$ & $0.129(2)$ \\
\hline C5 & $0.6905(3)$ & $-0.1453(2)$ & $0.4348(3)$ & $0.0780(12)$ \\
\hline O6 & $0.65265(16)$ & $-0.06831(13)$ & $0.44868(14)$ & $0.0709(7)$ \\
\hline $\mathrm{C} 7$ & $0.6982(2)$ & $-0.02294(19)$ & $0.49422(19)$ & $0.0576(9)$ \\
\hline $\mathrm{C} 8$ & $0.7762(2)$ & $0.0476(2)$ & $0.5297(2)$ & $0.0660(10)$ \\
\hline C9 & $0.8178(3)$ & $0.0028(3)$ & $0.5738(2)$ & $0.0745(11)$ \\
\hline $\mathrm{C} 10$ & $0.7844(3)$ & $0.0775(3)$ & $0.5824(2)$ & $0.0787(12)$ \\
\hline $\mathrm{C} 11$ & $0.7058(3)$ & $0.1012(2)$ & $0.5477(2)$ & $0.0717(11)$ \\
\hline $\mathrm{C} 12$ & $0.6602(2)$ & $0.05227(19)$ & $0.50438(18)$ & $0.0574(8)$ \\
\hline $\mathrm{C} 13$ & $0.5708(2)$ & $0.0777(2)$ & $0.4707(2)$ & $0.0598(9)$ \\
\hline $\mathrm{C} 14$ & $0.5800(2)$ & $0.15125(18)$ & $0.43111(19)$ & $0.0641(8)$ \\
\hline $\mathrm{C} 15$ & $0.6550(3)$ & $0.1485(3)$ & $0.3809(3)$ & $0.0833(15)$ \\
\hline $\mathrm{C} 16$ & $0.6325(3)$ & $0.0936(3)$ & $0.3245(3)$ & $0.0846(14)$ \\
\hline $\mathrm{C} 17$ & $0.5495(3)$ & $0.1175(3)$ & $0.2838(3)$ & $0.0791(12)$ \\
\hline N18 & $0.4579(2)$ & $0.11311(17)$ & $0.31929(17)$ & $0.0643(8)$ \\
\hline $\mathrm{C} 19$ & $0.4215(3)$ & $0.0321(2)$ & $0.3315(2)$ & $0.0623(10)$ \\
\hline $\mathrm{C} 20$ & $0.4291(2)$ & $-0.0193(2)$ & $0.2719(2)$ & $0.0618(9)$ \\
\hline $\mathrm{C} 21$ & $0.3799(4)$ & $-0.0015(3)$ & $0.2163(3)$ & $0.0910(15)$ \\
\hline $\mathrm{C} 22$ & $0.3910(6)$ & $-0.0436(4)$ & $0.1596(3)$ & $0.116(2)$ \\
\hline $\mathrm{C} 23$ & $0.4515(5)$ & $-0.1051(4)$ & $0.1579(3)$ & $0.1068(18)$ \\
\hline $\mathrm{C} 24$ & $0.5030(4)$ & $-0.1245(3)$ & $0.2121(3)$ & $0.0899(14)$ \\
\hline $\mathrm{C} 25$ & $0.4626(3)$ & $0.3714(2)$ & $0.5445(2)$ & $0.0968(15)$ \\
\hline $\mathrm{C} 26$ & $0.4987(3)$ & $0.3042(2)$ & $0.5024(2)$ & $0.0698(10)$ \\
\hline $\mathrm{O} 27$ & $0.5833(2)$ & $0.28749(17)$ & $0.50297(17)$ & $0.0933(10)$ \\
\hline $\mathrm{O} 28$ & $0.43554(17)$ & $0.26924(14)$ & $0.46908(14)$ & $0.0725(7)$ \\
\hline $\mathrm{C} 29$ & $0.1837(4)$ & $0.2600(4)$ & $0.3158(3)$ & $0.153(3)$ \\
\hline $\mathrm{C} 30$ & $0.2795(3)$ & $0.2235(2)$ & $0.3166(3)$ & $0.0822(13)$ \\
\hline $\mathrm{O} 31$ & $0.3097(2)$ & $0.19355(18)$ & $0.26585(16)$ & $0.0929(9)$ \\
\hline $\mathrm{O} 32$ & $0.32186(18)$ & $0.22728(16)$ & $0.37113(16)$ & $0.0834(9)$ \\
\hline
\end{tabular}

$U_{\text {eq }}=(1 / 3) \sum_{i} \Sigma_{j} U_{i j} a_{i}^{*} a_{j}^{*}\left(\boldsymbol{a}_{i} \cdot \boldsymbol{a}_{j}\right)$.

understand their synthetic, thermo-dynamic, selective-ion binding and structural properties of complex formation. ${ }^{3}$

The title compound was prepared from the reaction of [2,6Dioxa-14,18-diazatricyclo-[18.4.0.0 $\left.0^{7,12}\right]$-tetracosa-7,9,11, 20,22,24(1)-hexaene $(0.87 \mathrm{~g}, 2.69 \mathrm{mmol})$ and $\mathrm{Pd}\left(\mathrm{CH}_{3} \mathrm{CO}_{2}\right)_{2}$ $(0.60 \mathrm{~g}, 2.69 \mathrm{mmol})$ in $\mathrm{CH}_{2} \mathrm{Cl}_{2}(150 \mathrm{ml})$. The mixture was refluxed for $3 \mathrm{~h}$ and then the solution was cooled and filtered. The pale-yellow product was crystallized from a $\mathrm{CHCl}_{3} /$ hexane mixture (3:1), (yield $0.55 \mathrm{~g}, 63 \%$, decompose point $583 \mathrm{~K}$ ).

The X-ray analysis results are given in Tables $1-4$. The H3A, H3B, H4A, H4B, H8, H25A, H25B, H25C, H29A, H29B and $\mathrm{H} 29 \mathrm{C}$ atoms were positioned geometrically and refined by using a riding model; the remaining $\mathrm{H}$ atoms were located by a difference synthesis and refined isotropically.

The molecular structure of the title compound is shown in Fig. 2. The $\mathrm{Pd}(\mathrm{II})$ ion is at a distance of $-0.0062(2) \AA$ to the best plane of the N14, N18, O28, O32 atoms, and the coordination geometry of $\mathrm{Pd}(\mathrm{II})$ is square planar, which can be compared with the corresponding value of $-0.1060(3) \AA$ in $\{2,5$-dioxa13,16,19-triazatricyclo[19.4.0.0 $\left.0^{6,11}\right]$-pentacosa-6,8,10, 21,23,25(1)-hexaenediacetato palladium(II) $\cdot$ trihydrate. ${ }^{4}$ The average valance bond angle around $\mathrm{Pd}(\mathrm{II})$ is $90.02(13)^{\circ}$. The acetate ligands are bonded monodentately to the Pd(II) ion. On the other hand, the oxygen atoms of the acetate ligands are hydrogen bonded (Table 4) to the nitrogens of the 16-membered macrocyclic ring (Fig. 2). The acetate ligands are in the cisconfiguration. The nitrogens of the 16-membered macrocyclic ring are bonded bidentately to the $\mathrm{Pd}(\mathrm{II})$ ion. The nitrogen atoms in the 16-membered macro-cyclic ring are bonded bidentately, while no etheric oxygen atom is coordinated. This phenomenon has been found in several related complexes. ${ }^{4}$ The etheric oxygens are interestingly hydrogen bonded to each hydrogen of the benzylic $\mathrm{CH}_{2}$ groups (Fig. 2).

The molecule is made up of one bicyclic ring fused by a
Table 3 Selected bond distances $(\AA)$ and angles $\left({ }^{\circ}\right)$

\begin{tabular}{llllll}
\hline Pd & N18 & $2.035(3)$ & N18 & C17 & $1.487(5)$ \\
Pd & N14 & $2.041(3)$ & N18 & C19 & $1.496(5)$ \\
O2 & C1 & $1.356(5)$ & C26 & O27 & $1.229(5)$ \\
O2 & C3 & $1.442(6)$ & O28 & C26 & $1.270(4)$ \\
O6 & C7 & $1.369(4)$ & O28 & Pd & $2.031(3)$ \\
O6 & C5 & $1.441(4)$ & O31 & C30 & $1.231(5)$ \\
N14 & C13 & $1.493(5)$ & O32 & C30 & $1.266(5)$ \\
C15 & N14 & $1.476(6)$ & O32 & Pd & $2.025(3)$ \\
& & & & \\
O32-Pd-O28 & $82.08(10)$ & C13-N14-Pd & $111.2(2)$ \\
O32-Pd-N18 & $92.41(13)$ & C15-N14-Pd & $114.4(3)$ \\
O32-Pd-N14 & $175.11(14)$ & C17-N18-Pd & $112.8(3)$ \\
O28-Pd-N18 & $173.98(13)$ & C19-N18-Pd & $115.5(2)$ \\
O28-Pd-N14 & $93.49(13)$ & C26-O28-Pd & $128.8(3)$ \\
N18-Pd-N14 & $92.10(15)$ & C30-O32-Pd & $130.0(3)$ \\
& & & & \\
C1-O2-C3-C4 & $-163.5(5)$ & C16-C15-N14-C13 & $70.1(5)$ \\
C5-C4-C3-O2 & $-74.5(9)$ & N14-C15-C16-C17 & $64.9(5)$ \\
C3-C4-C5-O6 & $58.8(8)$ & N18-C17-C16-C15 & $-67.1(5)$ \\
C7-O6-C5-C4 & $176.6(4)$ & C19-N18-C17-C16 & $-72.9(5)$ \\
C5-O6-C7-C12 & $178.1(4)$ & C17-N18-C19-C20 & $-45.1(5)$ \\
C13-C12-C7-O6 & $4.5(5)$ & C1-C20-C19-N18 & $111.7(4)$ \\
N14-C13-C12-C7 & $-123.9(4)$ & C19-C20-C1-O2 & $5.4(5)$ \\
C15-N14-C13-C12 & $55.7(5)$ & C3-O2-C1-C20 & $-178.8(5)$ \\
\hline
\end{tabular}

Table 4 Hydrogen bonding geometry $\left(\AA{ }^{\circ}\right)$

\begin{tabular}{lclll}
\hline $\mathrm{D}-\mathrm{H} \cdots \mathrm{A}$ & $\mathrm{D}-\mathrm{H}$ & $\mathrm{H} \cdots \mathrm{A}$ & $\mathrm{D} \cdots \mathrm{A}$ & $\mathrm{D}-\mathrm{H} \cdots \mathrm{A}$ \\
\hline $\mathrm{N} 14-\mathrm{H} 141 \cdots \mathrm{O} 27$ & $0.87(4)$ & $1.90(4)$ & $2.738(5)$ & $162(4)$ \\
$\mathrm{N} 18-\mathrm{H} 181 \cdots \mathrm{O} 11$ & $0.80(3)$ & $1.95(3)$ & $2.731(4)$ & $163(3)$ \\
$\mathrm{C} 13-\mathrm{H} 132 \cdots \mathrm{O} 6$ & $0.99(3)$ & $2.29(3)$ & $2.774(4)$ & $108.7(2)$ \\
$\mathrm{C} 19-\mathrm{H} 191 \cdots \mathrm{O} 2$ & $0.91(3)$ & $2.32(3)$ & $2.753(5)$ & $109(3)$ \\
\hline
\end{tabular}

NPdN fragment and two acetate ligands. The 6-membered ring $\mathrm{A}(\mathrm{Pd} / \mathrm{N} 14 / \mathrm{C} 15 / \mathrm{C} 16 / \mathrm{C} 17 / \mathrm{N} 18)$ is in a slightly distorted chair conformation, as evidenced by the puckering parameters: ${ }^{5} \Phi_{2}=$ 152.8(5.5), $\theta_{2}=176.2(4)^{\circ}$, and $Q_{\mathrm{T}}=0.639(4) \AA$. The torsion angles of the 16-membered macrocycle (Table 3) have the sequence +sp, -ap, -ap, -sc, +sc, +ap, +ap, +sp, -ac, +sc, +sc, $+\mathrm{sc},-\mathrm{sc},-\mathrm{sc},-\mathrm{ap},+\mathrm{ac}$ (ap denotes antiperiplanar, sc synclinal, ac anticlinal and sp synperiplanar), corresponding to the $\mathrm{C} 20-\mathrm{C} 1, \ldots, \mathrm{C} 19-\mathrm{C} 20$ bond sequence. The conformations of the 6-membered and 16-membered macrocyclic rings are conditioned by the four hydrogen bonds (Fig. 2) and by the planarity of the two benzo-fused $\mathrm{O}-\mathrm{C}-\mathrm{C}-\mathrm{C}$ system.

\section{Acknowledgements}

The authors wish to acknowledge the Faculty of Arts and Sciences, Ondokuz Mayıs University, Turkey, for the use of the STOE IPDS II diffractometer (purchased under grant F.279 of the University Research Fund) and Hacettepe University Scientific Research Unit (grant number 0202602 002) for financial support.

\section{References}

1. Y. Jin, H. Yoon, J. Seo, J. Lee, S. Moon, J. Kim, S. W. Han, K. Park, L. F. Lindoy, and S. S. Lee, J. Chem. Soc. Dalton Trans., 2005, 788 .

2. L. F. Lindoy, Pure Appl. Chem., 1997, 69, 2179.

3. K. R. Adam, D. S. Baldwin, L. F. Lindoy, G. V. Meehan, I. M. Vasilescu, and G. Wei, Inorg. Chim. Acta, 2003, 352, 46.

4. S. Bilge, Z. Kılıç, T. Hökelek, and B. Erdoğan, J. Mol. Struct., 2004, 691, 85.

5. D. Cremer and J. A. Pople, J. Am. Chem. Soc., 1975, 971, 354. 